\title{
Intraoperative surveillance of the vertebral artery using indocyanine green angiography and Doppler sonography in craniovertebral junction surgeries
}

\author{
Dong Hoon Lee, MD, ${ }^{1}$ Jong Hyeok Park, MD, ${ }^{2}$ Jung Jae Lee, MD, ${ }^{3}$ Jong Beom Lee, MD, ${ }^{4}$ \\ Ho Jin Lee, MD, PhD, ${ }^{1}$ I Sup Kim, MD, PhD, ${ }^{1}$ Jung Woo Hur, MD, PhD, ${ }^{5}$ and \\ Jae Taek Hong, MD, PhD 5
}

\begin{abstract}
${ }^{1}$ Department of Neurosurgery, St. Vincent's Hospital, The Catholic University of Korea, Suwon; 'Department of Neurosurgery, Incheon St. Mary's Hospital, The Catholic University of Korea, Incheon; ${ }^{3}$ Department of Neurosurgery, Kangneung Asan Hospital, The Ulsan University, Kangneung; ${ }^{4}$ Department of Neurosurgery, Chungbuk National University of Korea, Suwon; and ${ }^{5}$ Department of Neurosurgery, Eunpyeong St. Mary's Hospital, The Catholic University of Korea, Seoul, Korea
\end{abstract}

\begin{abstract}
OBJECTIVE The authors sought to evaluate the usefulness of indocyanine green (ICG) angiography and Doppler sonography for monitoring the vertebral artery (VA) during craniovertebral junction (CVJ) surgery and compare the incidence of VA injury (VAI) between the groups with and without the monitoring of VA using ICG angiography and Doppler sonography.

METHODS In total, 344 consecutive patients enrolled who underwent CVJ surgery. Surgery was performed without intraoperative VA monitoring tools in 262 cases (control group) and with VA monitoring tools in 82 cases (monitoring group). The authors compared the incidence of VAI between groups. The procedure times of ICG angiography, change of VA flow velocity measured by Doppler sonography, and complication were investigated.
\end{abstract}

RESULTS There were $4 \mathrm{VAI}$ cases in the control group, and the incidence of VAI was $1.5 \%$. Meanwhile, there were no $\mathrm{VAI}$ cases in the monitoring group. The procedure time of ICG angiography was less than 5 minutes (mean [ \pm SD] 4.6 \pm 2.1 minutes) and VA flow velocity was $11.2 \pm 4.5 \mathrm{~cm} / \mathrm{sec}$. There were several cases in which the surgical method had to be changed depending on the VA monitoring. The combined use of ICG angiography and Doppler sonography was useful not only to monitor VA patency but also to assess the quality of blood flow during CVJ surgery, especially in the high-risk group of patients.

CONCLUSIONS The combined use of ICG angiography and Doppler sonography enables real-time intraoperative monitoring of the VA by detecting blood flow and flow velocity. As the arteries get closer, they provide auditory and visual feedback to the surgeon. This real-time image guidance could be a useful tool, especially for high-risk patients and inexperienced surgeons, to avoid iatrogenic VAI during any CVJ surgery.

https://thejns.org/doi/abs/10.3171/2020.10.FOCUS20770

KEYWORDS vertebral artery injury; complication; monitoring; indocyanine green angiography; Doppler sonography; craniovertebral junction

$\mathrm{T}$ HE surgical approach for craniovertebral junction $(\mathrm{CVJ})$ procedures may be complicated for many reasons due to sensitive relationships involved in the surrounding neurovascular structures and complex biomechanical issues. ${ }^{1-6}$ The risk of vertebral artery injury (VAI) during CVJ surgery is highly variable. . $^{17,8}$ Operative difficulties and risks increase from individual differences of bony structures and variance of the vertebral artery (VA) ${ }^{2,9-16}$
Iatrogenic VAI (IVAI) is a serious complication of cervical spine surgery, with the potential to cause catastrophic bleeding, permanent neurological impairment, and even death. Most of the VAI cases reported in the literature occurred during surgical exposure or insertion of instrumentation. ${ }^{1,8}$ Therefore, it is necessary to discuss ways to avoid IVAI. However, there has been scant information about real-time evaluation techniques to monitor VA patency during surgical procedures.

ABBREVIATIONS CVJ = craniovertebral junction; HRVA = high-riding VA; ICG = indocyanine green; IVAI = iatrogenic VAI; PICA = posterior inferior cerebellar artery; RA = rheumatoid arthritis; TF = transverse foramen; $\mathrm{VA}=$ vertebral artery; $\mathrm{VAl}=\mathrm{VA}$ injury.

SUBMITTED August 29, 2020. ACCEPTED October 23, 2020.

INCLUDE WHEN CITING DOI: 10.3171/2020.10.FOCUS20770. 
Indocyanine green (ICG) angiography is a novel diagnostic procedure that allows real-time evaluation of blood flow, especially during vascular surgery. ${ }^{17,18}$ Intraoperative ICG angiography has been reported as a valuable addition to prevent vessel injury during cerebrovascular neurosurgery. ICG angiography can monitor blood flow patency, but not blood flow patterns. It is known that Doppler sonography can provide a reliable assessment of blood flow patterns in real time..$^{19,20}$

The purpose of this study was to evaluate the usefulness of ICG angiography and Doppler sonography for the monitoring of VA patency during posterior cervical spine surgery and compare the incidence of VAI between the groups with and without the monitoring of VA using ICG angiography and Doppler sonography.

\section{Methods}

After obtaining approval from our institutional review board, which waived the need for informed consent, patient data were retrospectively reviewed.

\section{Patient Demographics}

This is a retrospective study of consecutive patients who had undergone CVJ surgeries between January 2005 and January 2020 at our institute. In total, 344 consecutive patients who underwent CVJ surgeries were enrolled in this study group. All patients underwent 3D CTA preoperatively to evaluate the risk of VAI. In the high-risk group of the VAI, we performed ICG angiography and Doppler sonography intraoperatively to monitor VA patency in patients who underwent surgery between February 2012 and January 2020.

Regarding CVJ surgery, the following factors were found to identify the high-risk VAI group: 1) high-riding VA (HRVA) at the level of the C2 vertebra, 2) narrow C2 pedicle, 3) V3-segment anomaly, and 4) surgeon uncertainty regarding the location of the VA during surgery. An HRVA was defined as an isthmus height of $5 \mathrm{~mm}$ or less and/or internal height of $2 \mathrm{~mm}$ or less on a sagittal image obtained $3 \mathrm{~mm}$ lateral to the cortical margin of the spinal canal wall at $\mathrm{C} 2$. A narrow pedicle was defined using the pedicle width, measured on axial CT scans at the levels wherein the cortical margin of the pedicle was clearly observed. A narrow $\mathrm{C} 2$ pedicle was considered present when the largest pedicle width was $4 \mathrm{~mm}$ or less, because the diameter of commonly used screws is 4.0 or $3.5 \mathrm{~mm} .^{4,21}$ Additionally, when the patient's pathology is related to tumor, infection, rheumatoid arthritis (RA), congenital anomaly, or revision surgery, the surgeon may not be sure where the VA is located.

Three types of V3 segment anomalies have been reported in the literature: persistent intersegmental artery, fenestrated VA, and early branch of the posterior inferior cerebellar artery (PICA), ${ }^{2,9,12}$

All surgeries were performed by the senior author (J.T.H.). The surgical procedure used for atlantoaxial fixation involved segmental rod-screw fixation using $\mathrm{C} 1$ lateral mass screws and $\mathrm{C} 2$ pedicle/laminar/pars screws with or without posterior wiring. An occipital plate/screw system was used when occipital fixation was required.
CVJ fixation was performed with the patient in a neutral posture when possible to prevent swallowing difficulties after surgery.

Intraoperative ICG of the VA was performed using a commercially available surgical microscope (OPMI Pentero, Carl Zeiss). Briefly, after the intravenous injection of ICG, the operative field is illuminated with near-infrared light. A real-time angiographic image of the VA, with its arterial, capillary, and venous phases, is seen on the video screen and recorded for further analysis. Playback loops can be repeated as needed. A dose of 0.2 to $0.5 \mathrm{mg} / \mathrm{kg}$ is recommended for VA ICG, with a maximum daily dose limit of $5 \mathrm{mg} / \mathrm{kg}$.

ICG and Doppler sonography were used in intraoperative assessment of the exact location of the VA. Also, Doppler probing was performed during subperiosteal muscle dissection around the $\mathrm{C} 1$ arch, stepwise drilling, and tapping. Since VA injuries usually occur inside of bone where the VA cannot be visualized, Doppler sonography enables monitoring of the VA by detecting blood flow and blood flow velocity as the arteries get closer and providing auditory and visual feedback to the surgeon. Thus, inadequate lateral deviation of the screw trajectory can be easily detected by intraoperative Doppler sonography because the surgeon can get auditory, visual, and tactile feedback simultaneously when the screw trajectory is directed toward the VA inside the transverse foramen (TF) during $\mathrm{C} 1$ and $\mathrm{C} 2$ instrumentation. Blood flow velocity in the V3 segment of the VA was recorded before screw fixation as a baseline, of which value was compared with blood flow velocity during and after posterior instrumentation.

Patients were divided into two groups according to whether VA monitoring was performed during surgery: the control group, who underwent surgery without VA monitoring; and the monitoring group, who underwent surgery with VA monitoring. We compared the incidence of VAI between two groups.

All patients underwent postoperative $\mathrm{CT}$ to evaluate bone fusion and screw breech into the TF and postoperative status. In the group with a high risk of VAI, we performed CTA to evaluate the VA patency. We also investigated the procedure time of ICG angiography, change of VA flow velocity using Doppler sonography, and complications and limitations of ICG angiography and Doppler sonography.

\section{Statistical Analysis}

SPSS software version 17.0 (SPSS Inc.) was used for statistical analysis. We used the chi-square test to assess the difference in disease distribution between the two groups; $\mathrm{p}<0.05$ was considered statistically significant.

\section{Results}

A total of 344 patients were enrolled in this study (Table 1). The mean $( \pm \mathrm{SD})$ patient age was $58.6 \pm 16.7$ years, and 166 patients (48.3\%) were male and 178 patients $(51.7 \%)$ were female. The types of surgery were fixation of CVJ $(n=295,85.8 \%)$, treatment of tumor or infection $(n=$ $25,7.3 \%)$, and decompression around CVJ $(n=24,7.0 \%)$. 
TABLE 1. Demographic characteristics of the patients

\begin{tabular}{lccc}
\hline \multicolumn{1}{c}{ Characteristic } & Total & Monitoring Group & Control Group \\
\hline No. of patients & 344 & 82 & 262 \\
\hline Age, yrs & $58.6 \pm 16.7$ & $60.0 \pm 17.5$ & $57.8 \pm 16.2$ \\
\hline Sex & & & \\
\hline Male & $166(48.3)$ & $30(36.6)$ & $136(51.9)$ \\
\hline Female & $178(51.7)$ & $52(63.4)$ & $126(48.1)$ \\
\hline VAl & $4(1.2)$ & 0 & $4(1.5)$ \\
\hline Surgery & & & \\
\hline CVJ fixation & $295(85.8)$ & $67(81.7)$ & $228(87.0)$ \\
\hline Tumor/infection & $25(7.3)$ & $13(15.9)$ & $12(4.6)$ \\
\hline Decompression & $24(7.0)$ & $2(2.4)$ & $22(8.4)$ \\
\hline
\end{tabular}

Values are presented as number (\%) of patients or mean $\pm \mathrm{SD}$.

The causes of CVJ pathologies were instability, infection, tumor, Chiari malformation/syrinx, myelopathy, or congenital anomaly. There was a statistically significant difference in disease distribution between the two groups (Table 2).

Surgery was performed without the aid of intraoperative VA monitoring tools in 262 cases (control group) and with intraoperative VA monitoring tools in 82 cases (monitoring group). Of the 262 patients in the control group, 136 patients $(51.9 \%)$ were male and 126 patients $(48.1 \%)$ were female. The types of surgery were CVJ fixation ( $\mathrm{n}=$ $228,87.0 \%)$, tumor or infection surgery $(\mathrm{n}=12,4.6 \%)$, and decompression around the CVJ $(n=22,8.4 \%)$.

The most common pathology of the control group patients was instability (63.7\%), followed by myelopathy (20.2\%), congenital anomaly (8.4\%), tumor (3.1\%), Chiari malformation/syrinx (3.1\%), and infection (1.5\%).

There were 82 patients in the monitoring group (52 females and 30 males) and their mean age was $60.0 \pm 17.5$ years (range 19-89 years). The most common pathologies in the monitoring group patients were instability (50.0\%), congenital malformations $(26.8 \%)$, tumors $(14.6 \%)$, myelopathy $(7.3 \%)$, and infection (1.2\%). In the monitoring group with a high risk of VAI, ICG angiography and Doppler sonography were performed. No cases of VAI occurred during surgery in the monitoring group. There were 4 cases of VAI in the control group, and the incidence of VAI in the control group was $1.5 \%$. One VAI patient developed VA occlusion in the $\mathrm{C} 1 \mathrm{TF}$ during $\mathrm{C} 1$ screw fixation. The second patient developed VA rupture during $\mathrm{C} 2$ pedicle tapping. In this patient, the $\mathrm{C} 2$ pedicle screw was inserted to control severe bleeding and occlude the VA in the C2 TF. Fortunately, due to the good contralateral VA flow in both of these patients no neurological complications occurred after VAI. However, the third patient suffered a brainstem infarct due to VA occlusion caused by $\mathrm{C} 2$ pedicle screw violation of the $\mathrm{C} 2 \mathrm{TF}$ (Fig. 1), and the fourth patient died of a severe cerebellar/brainstem infarction.

The procedure duration of ICG angiography was less than 5 minutes (mean $4.6 \pm 2.1$ minutes), and the Doppler sonography data show that the mean VA flow velocity was $11.2 \pm 4.5 \mathrm{~cm} / \mathrm{sec}$. Preoperative CTA findings were correlated with ICG angiography findings. Combined ICG angiography and Doppler sonography were useful not only to monitor VA patency but also to assess the quality of blood flow during various types of CVJ surgery, especially in the cases with an HRVA $(40 / 82,48.8 \%)$, narrow C2 pedicle (38/82, 46.3\%), and V3 segment anomaly $(20 / 82,24.4 \%)$, respectively (Table 3 ). There were 40 cases $(48.8 \%)$ with combined risk factors, and 52 cases $(63.4 \%)$ in the monitoring group had at least one of the following risk factors: HRVA, narrow $\mathrm{C} 2$ pedicle, or V3 segment anomaly. It is especially helpful to identify the exact location and flow of VA in patients with V3 segment anomaly or HRVA, and when surgery is performed on tumors or infections around the CVJ. In our patients in the monitoring group there were several cases in which the surgical method had to be changed during the surgery based on the VA monitoring. One case of an adverse skin reaction resulted due to the ICG leakage outside the vessel during the injection.

\section{Illustrative Cases Case 1}

A 66-year-old female patient presented with a hand-tingling sensation and clumsiness with os odontoideum (Fig. 1). Her preoperative imaging study showed a relatively narrow $\mathrm{C} 2$ pedicle on the right side. We planned treatment with $\mathrm{C} 1-3$ posterior instrumentation and inserted a pedicle screw at $\mathrm{C} 2$ and a lateral mass screw at $\mathrm{C} 1$ and C3, without any intraoperative adverse events. However, the patient complained of left-sided weakness 2 weeks after the surgery. Postoperative MRI showed a brainstem infarction from VA occlusion caused by the inferiorly directed $\mathrm{C} 2$ pedicle screw.

TABLE 2. Pathologies of the patients

\begin{tabular}{lcccr}
\hline \multicolumn{1}{c}{ Pathology } & Total $(\mathrm{n}=344)$ & Monitoring Group $(\mathrm{n}=82)$ & Control Group $(\mathrm{n}=262)$ & $\mathrm{p}$ Value \\
\hline Instability & $208(60.5)$ & $41(50)$ & $167(63.7)$ & 0.026 \\
\hline Infection & $5(1.5)$ & $1(1.2)$ & $4(1.5)$ & 0.839 \\
\hline Tumor & $20(5.8)$ & $12(14.6)$ & $8(3.1)$ & $<0.001$ \\
\hline Chiari/syrinx & $8(2.3)$ & $0(0)$ & $8(3.1)$ & 0.398 \\
\hline Myelopathy & $59(17.2)$ & $6(7.3)$ & $53(20.2)$ & 0.007 \\
\hline Congenital anomaly & $44(12.8)$ & $22(26.8)$ & $22(8.4)$ & $<0.001$ \\
\hline
\end{tabular}

Values are presented as number (\%) of patients unless otherwise indicated. 


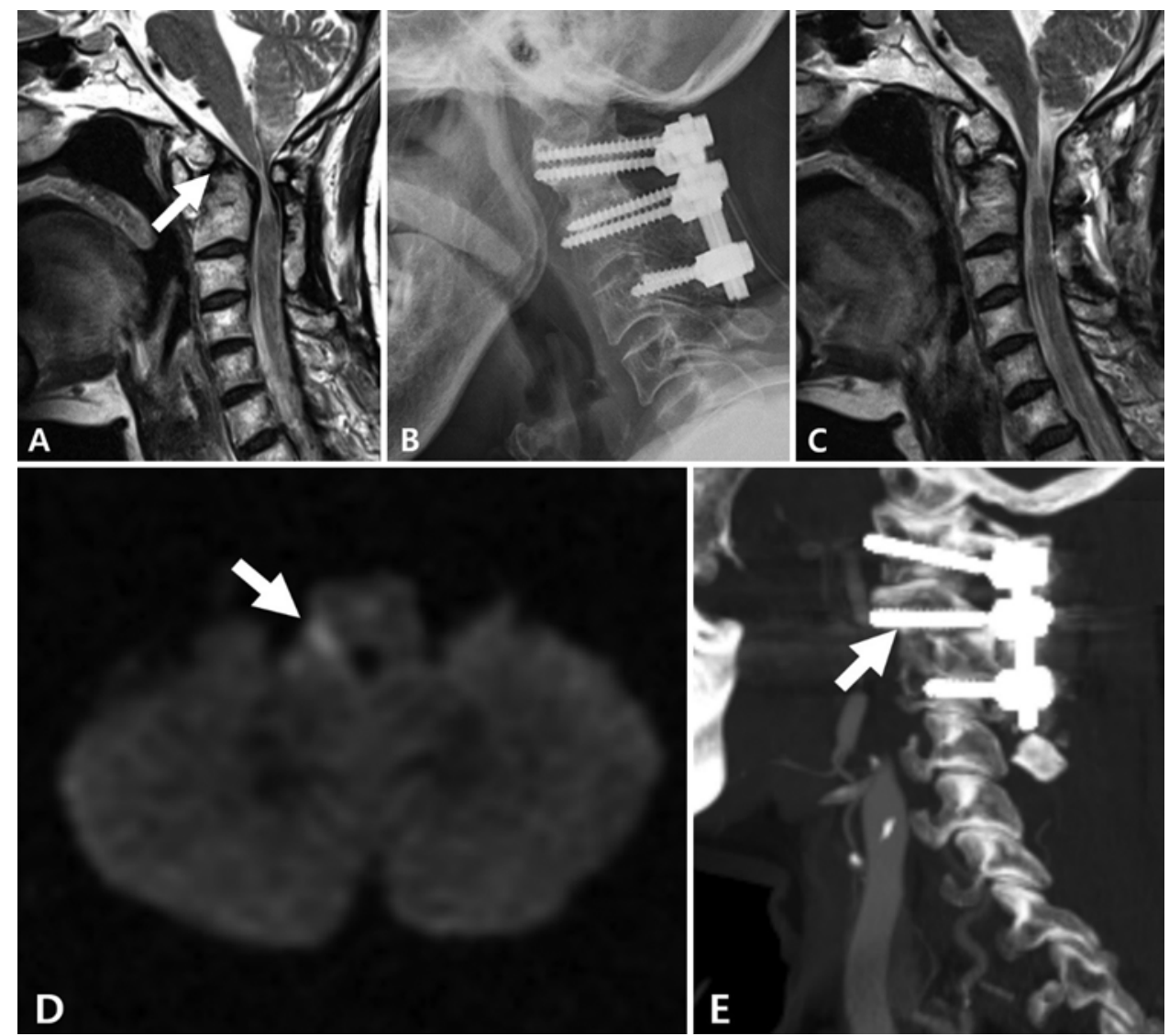

FIG. 1. Case 1. A: Preoperative sagittal T2-weighted MR image demonstrating os odontoideum (white arrow), spinal cord compression, and T2 signal abnormality within the cord around the cervicomedullary junction. B: Postoperative lateral radiograph demonstrating C1-3 posterior instrumentation and fusion. C: Postoperative sagittal MR image demonstrating a reduction of C1-2 subluxation and decompression of the spinal cord. D: Postoperative MR diffusion image shows high signal intensity (white arrow) around the right side of the medulla. E: Postoperative sagittal CT image demonstrating the right C2 screw breach into the C2 TF (white arrow).

\section{Case 2}

A 51-year-old female patient presented with neck pain and progressive quadriparesis. The preoperative MRI demonstrated Chiari malformation and a huge syringomyelia at the cervicothoracic spine (Fig. 2). The 3D CTA showed a left V3 segment anomaly. We wanted to identify the exact location of the V3 and V4 segments of the left VA to avoid VAI during foramen magnum decompression,

TABLE 3. Morphological risk factors of VAl in the monitoring group

\begin{tabular}{lc}
\hline \multicolumn{1}{c}{ Risk Factor } & Monitoring Group $(\mathrm{n}=82)$ \\
\hline V3 segment anomaly & $20(24.4)^{*}$ \\
\hline HRVA & $40(48.8)$ \\
\hline Narrow C2 pedicle & $38(46.3)$ \\
\hline Combined & $40(48.8)$ \\
\hline None & $30(36.6)$ \\
\hline
\end{tabular}

Values are presented as number (\%) of patients.

* Persistent first intersegmental artery in 16 cases, early branch of the PICA in 2 cases, and fenestration in 2 cases.
C1 laminectomy, and duraplasty. Intraoperatively, the abnormal course of the left VA was identified by ICG angiography and Doppler ultrasonography, which was highly informative to decide the location of bony decompression/ duraplasty and to avoid VA injury. Postoperatively, her neurological disturbances gradually improved.

\section{Case 3}

A 66-year-old male patient presented with bilateral arm paresthesia and clumsiness with atlantoaxial instability and os odontoideum (Fig. 3). Preoperative CTA showed that there was a persistent first-intersegment anomaly on the left side, and therefore we planned to use different $\mathrm{C} 1$ screw fixation techniques than those used in patients without this anomaly. We made the entry point at the $\mathrm{C} 1$ posterior arch for the left $\mathrm{C} 1$ screw and at the $\mathrm{C} 1$ lateral mass for the right $\mathrm{C} 1$ screw. Intraoperatively, the precise location of the left V3 segment anomaly was identified using ICG angiography and Doppler ultrasonography to avoid VA injury. Intraoperative Doppler sonography showed that VA flow and velocity significantly changed on the left side during the C1-2 cable fixation. Thus, we had to change the surgical strategy to avoid VA injury and 


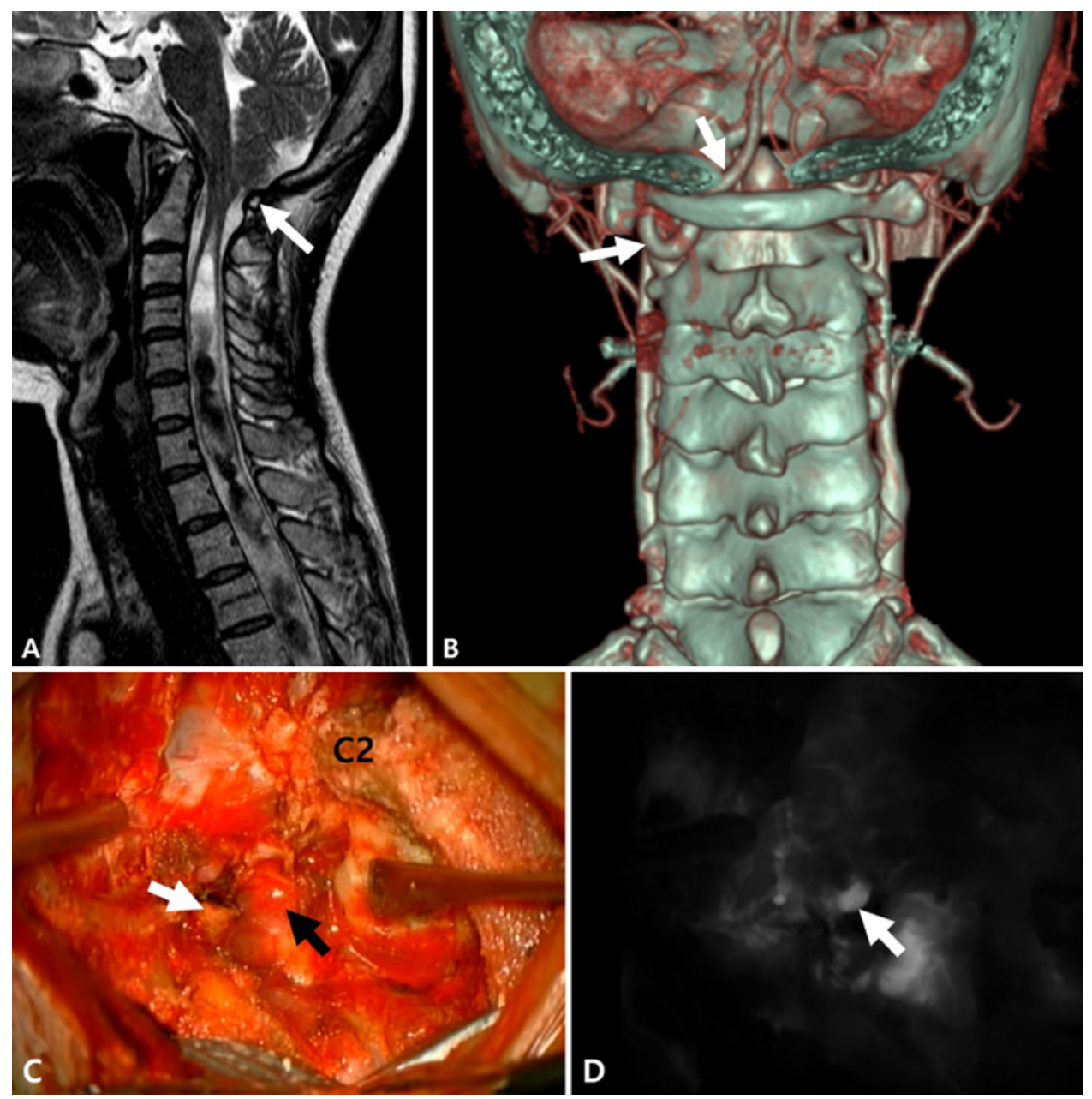

FIG. 2. Case 2. A: Preoperative sagittal T2-weighted MR image demonstrating Chiari malformation (white arrow) and a huge syringomyelia at the cervicothoracic spine. B: A 3D CTA image demonstrating a left-sided V3 segment anomaly (arrows) below the $\mathrm{C} 1$ arch. C: The patient underwent a suboccipital craniectomy and C1 laminectomy with duraplasty. Intraoperative photograph showing the remaining $\mathrm{C} 1$ lamina (white arrow) after posterior decompression and the persistent first intersegmental artery (black arrow) below the C1 arch. D: ICG angiographic image demonstrating a V3 segment anomaly (white arrow) of the VA during duraplasty.

perform unilateral cable fixation on the right side. Postoperatively, the patient's neurological disturbances gradually improved without complications.

\section{Case 4}

A 74-year-old male patient presented with neck pain and occipital headache. The patient was known to have had RA for several years. A preoperative sagittal reconstructed CT image showed bilateral HRVAs and a narrow $\mathrm{C} 2$ pedicle due to rheumatoid mutilation of the left $\mathrm{C} 1-2$ facet joint (Fig. 4). In this patient, we planned to use bilateral C2 pars screws due to the HRVA. Intraoperatively, Doppler ultrasonography was used as an additional intraoperative tool, providing real-time identification of the VA and enabling the surgeon to decide the adequate length of the $\mathrm{C} 2$ pars screw to preserve the VA inside of the $\mathrm{C} 2$. A postoperative sagittal reconstructed $\mathrm{CT}$ scan showed that the endpoint of left $\mathrm{C} 2$ pars screw is located just behind the C2 TF. During drilling and tapping for the C2 screw, it was important to maintain continuous awareness of auditory feedback (Doppler sonography) as well as tactile feedback to avoid pushing the screw into the $\mathrm{C} 2 \mathrm{TF}$ and damaging the VA inside.

\section{Discussion}

Iatrogenic VAI (IVAI) is a rare but potentially serious complication of CVJ surgeries, with the potential to cause fatal bleeding, permanent neurological impairment, and even death. ${ }^{1,8}$ Reported rates of IVAI vary depending on the surgical approach, the level of surgery, and the instrumentation techniques. The incidence of IVAI is much higher in posterior surgery than in anterior cervical surgery. ${ }^{22-24}$ A previous multicenter study showed that the overall occurrence of IVAI was $0.08 \%$ in all cervical spine surgeries. ${ }^{1}$ Screw misplacement was correlated to $69 \%$ of IVAI cases, $54 \%$ of which occurred during the placement of the $\mathrm{C} 1$ lateral mass screw or the $\mathrm{C} 2$ pedicle screw. ${ }^{1}$ Posterior surgery of the upper cervical spine (C3 

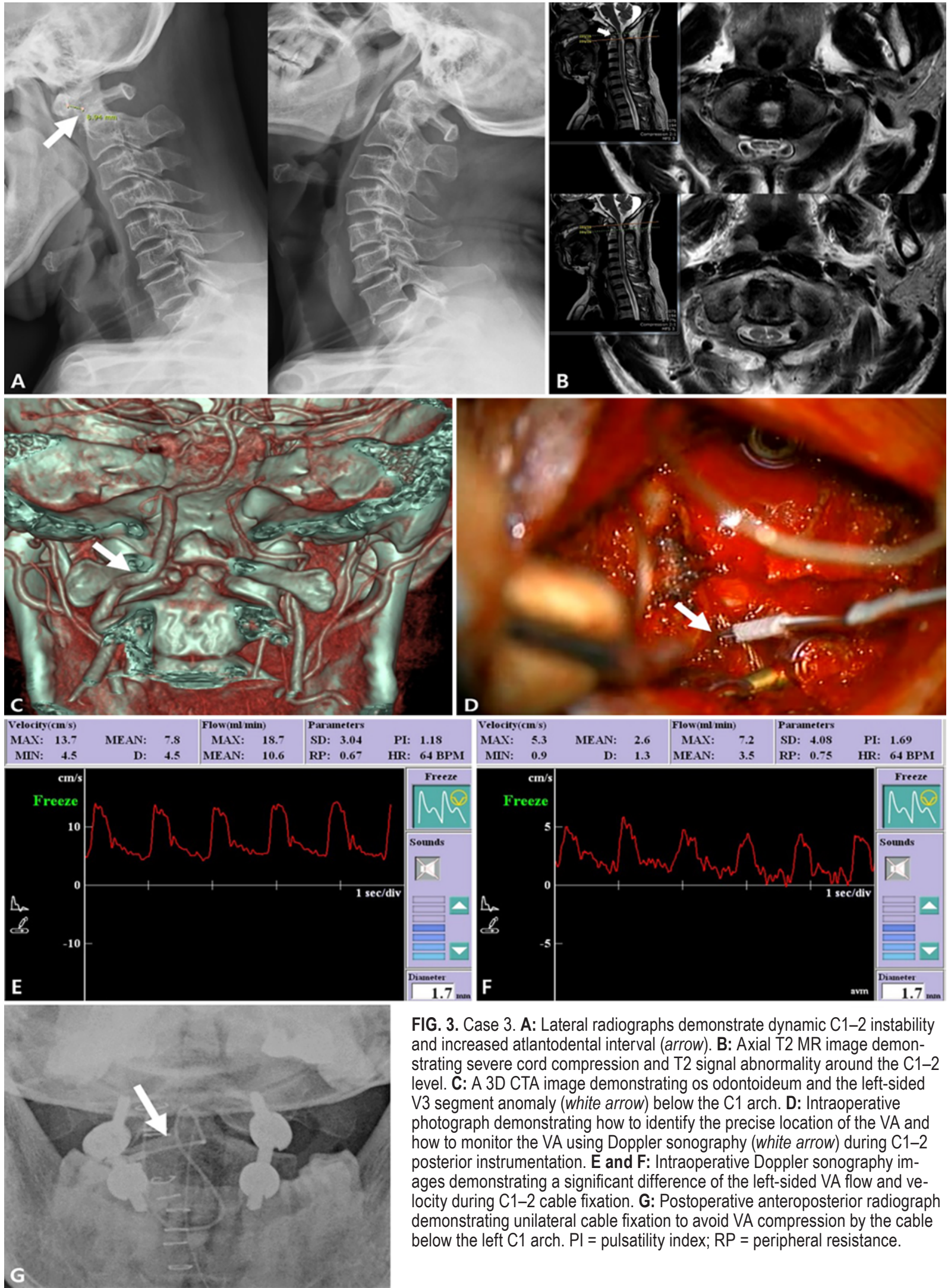

FIG. 3. Case 3. A: Lateral radiographs demonstrate dynamic C1-2 instability and increased atlantodental interval (arrow). B: Axial T2 MR image demonstrating severe cord compression and T2 signal abnormality around the C1-2 level. C: A 3D CTA image demonstrating os odontoideum and the left-sided V3 segment anomaly (white arrow) below the C1 arch. D: Intraoperative photograph demonstrating how to identify the precise location of the VA and how to monitor the VA using Doppler sonography (white arrow) during C1-2 posterior instrumentation. E and F: Intraoperative Doppler sonography images demonstrating a significant difference of the left-sided VA flow and velocity during C1-2 cable fixation. G: Postoperative anteroposterior radiograph demonstrating unilateral cable fixation to avoid VA compression by the cable below the left $\mathrm{C} 1$ arch. $\mathrm{PI}=$ pulsatility index; $\mathrm{RP}=$ peripheral resistance. 
to occiput) were reported to pose the most significant IVAI risk. ${ }^{25}$ These results suggest that CVJ surgery could be a high-risk procedure for IVAI. Despite these risks, there has been no definite method to monitor the patency and flow characteristics of VA during CVJ surgery.

Although multimodal intraoperative monitoring (MIOM) can provide early detection of neurological impairments during spinal surgery, MIOM is not sufficient to detect VA injury immediately during surgery in terms of anatomy and monitoring time. ${ }^{26-28}$ Therefore, additional intraoperative tools are necessary to monitor the VA and prevent complications related to VAI.

In 1955, Kodak Research Laboratories developed an ICG for near-infrared photography, approved for clinical use. ${ }^{17,18,29}$ After the first publications of Raabe and colleagues, ICG angiography promptly became the standard technique for intraoperative identification of mis-clippings in most cerebrovascular neurosurgery. ${ }^{18,29,30}$

The use of ICG angiography in spinal surgery has also been generally used for spinal dural arteriovenous fistulas, intradural spinal tumors, and intramedullary cavernous malformations. ${ }^{31-34}$ However, ICG angiography has displayed limitations, such as difficulties in visualizing vascular structures in deeper planes or inside of bony structures, as well as the ability to visualize only vessels within the operative microscopic field. ${ }^{35,36}$ Moreover, ICG angiography can only monitor the patency of VA but not the quality of VA blood flow. To overcome these limitations of ICG angiography, we used Doppler sonography in combination for the intraoperative assessment of VA and blood flow patterns, which provided a real-time and repeatable way to detect unexpected stenosis or occlusion of VA by surgical devices.

In general, the risk of VAI may vary for each different pathology and each surgeon. ${ }^{1,37}$ This variation occurs not only because the incidence of significant complications declines with the increase in the surgeon's experience, but also because the VA's status and related complications may be changed by certain pathologic conditions such as a tumor, trauma, congenital anomaly, and infection. ${ }^{2,6,9,10,15,38-40}$

In the present study, the control and monitoring groups differed in terms of pathology and VAI risk. We performed ICG angiography and Doppler sonography only for patients with a high risk of VAI. High-risk groups included patients with the following risk factors: 1) HRVA at the level of the $\mathrm{C} 2$ vertebra, 2) a narrow $\mathrm{C} 2$ pedicle, 3) a V3 segment anomaly, and 4) surgeon uncertainty regarding the location of the VA during surgery because the patient's pathology was related to tumor, infection, RA, congenital anomaly, or revision surgery.

The vulnerability of the VA may be changed by certain pathologic conditions, such as tumor, infection, congenital anomaly, and revision surgery. Moreover, the incidence of VA anomaly could be higher in patients with a congenital anomaly. ${ }^{2,9,13,41}$ Our data showed that the incidences of surgery for tumor and congenital anomaly were significantly higher in the monitoring group (Table 2). Fifty-two patients $(63.4 \%)$ in the monitoring group had at least one of the following risk factors: HRVA, a narrow $\mathrm{C} 2$ pedicle, or a V3 segment anomaly (Table 3 ). There were 13 cases $(15.8 \%)$ with tumor or infection and 7 cases $(8.5 \%)$ of revi- sion surgery in the monitoring group. Nonetheless, despite the risk factors present in the monitoring group, no VAI occurred during the CVJ surgery in these patients.

Although the single-surgeon experience in this study may limit the ability to generalize results to the entire population undergoing CVJ surgery, these data may show the pattern of complications in this highly specific type of surgery, and the findings suggest that VA-related complications could be reduced by the use of combined ICG angiography and Doppler sonography, even in this highrisk group of VAI.

The best treatment for VAI is prevention. Thorough preoperative assessment of the cervical spine and VA status for anomalies or pathologic changes, especially in patients with degeneration, RA, tumors, infection, or congenital bony anomalies, can help avoid VAI.

When anomalies are recognized before surgery, surgeons may consider intraoperative CT or 3D fluoroscopybased navigation systems, which can help determine the accurate anatomy when landmarks are lost while assisting decompression and instrument placement. However, there are many potential sources of error with navigation technique that can result in less accurate screw placement, especially in the cervical spine. The mobility of the cervical spine relative to the reference frame may cause errant screw placement. Additional concerns with intraoperative navigation are the increased setup time, disruption of workflow, radiation exposure, and high cost. Moreover, navigation-guided surgery is limited to being a morphometry-based guiding technique and cannot be used to evaluate the real-time patency and blood flow of the VA.

ICG angiography can enable monitoring of the patency of the VA and help determine the precise surgical location of the VA. However, ICG angiography has critical limitations, such as visualizing difficulties of vascular structures in deeper planes and monitoring only the patency of the VA but not the quality of the VA blood flow. Doppler sonography enables monitoring of the VA by detecting blood flow and blood flow velocity as the arteries get closer and providing auditory and visual feedback to the surgeon.

Thus, inadequate lateral deviation of the screw trajectory can be easily detected by intraoperative Doppler sonography because the surgeon can get auditory, visual, and tactile feedback simultaneously when the screw trajectory is directed to the TF during $\mathrm{C} 1$ and $\mathrm{C} 2$ instrumentation. ${ }^{42}$ Moreover, intraoperative Doppler sonography is useful for accurately measuring the length of the $\mathrm{C} 2$ pars screw so as not to violate the $\mathrm{C} 2 \mathrm{TF}$. When the surgeon places the C2 pars screw in patients with HRVA, Doppler probing can identify the VA inside the $\mathrm{C} 2 \mathrm{TF}$, which is useful for determining the length of the screw, enabling the surgeon to prevent over-drilling and selecting an excessively long C2 screw (Fig. 4).

The combined use of ICG angiography and Doppler sonography enables real-time intraoperative monitoring of the VA by detecting vessel patency, blood flow, and flow velocity. As the arteries get closer, auditory and visual feedback is provided to the surgeon. This real-time image guidance can be a useful tool, especially for high-risk patients and inexperienced surgeons, to avoid IVAI during any CVJ surgery. 

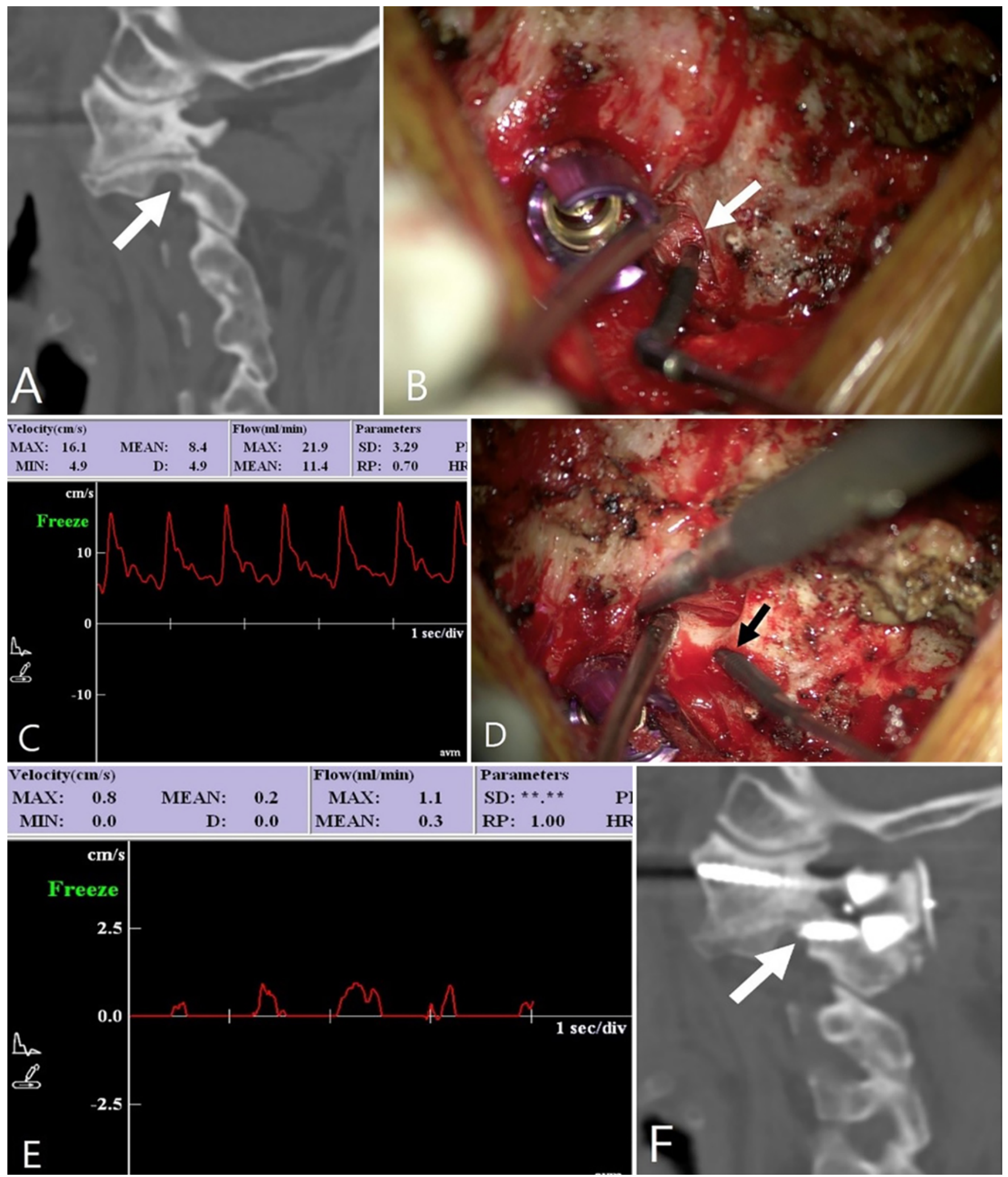

FIG. 4. Case 4. A: Preoperative sagittal reconstructed CT image showing an HRVA (arrow) and narrow C2 pedicle due to the mutilation of the left C1-2 facet joint caused by the patient's RA. B: Intraoperative photograph demonstrating the monitoring of the VA around the left C2 TF (arrow). C: Intraoperative Doppler image showing the measurement of flow velocity $(\mathrm{cm} / \mathrm{sec})$ and blood flow $(\mathrm{ml} / \mathrm{min})$. The mean flow velocity of the left VA is $8.4 \mathrm{~cm} / \mathrm{sec}$. D: Intraoperative photograph demonstrating that the tip of the Doppler sonography (arrow) is located inside the C2 screw hole to identify the VA and measure the adequate length of the $\mathrm{C} 2$ pars screw to avoid VA injury. E: Intraoperative Doppler sonography image showing no evidence of arterial blood flow inside the screw hole. F: Postoperative sagittal reconstructed CT scan showing that the endpoint of the C2 pars screw is located just behind the C2 TF. 


\section{Study Limitations}

This study has several limitations that warrant consideration. First, it is limited by its retrospective, single-surgeon design, which may have caused selection bias. Second, the sample size and the incidences of VAI here may be relatively small to draw meaningful conclusions. Third, the total number of patients in each group was biased, and case etiologies of each of the groups were heterogeneous (Table 2), making it difficult to simply compare VAI incidence between the two groups. Fourth, we did not evaluate clinical outcomes. Fifth, the blood flow and velocities of VAs could be different between each patient and each location side of the VAs. Therefore, there is a lack of baseline data for the normal blood flow and velocity of the VAs in this study. Because of these limitations, we suggest that a multicenter, larger-scale study be performed to obtain more accurate information on the value of this combined intraoperative monitoring technique to prevent VAI after CVJ surgery.

\section{Conclusions}

Compared with digital subtraction angiography, ICG angiography requires less time, personnel, and equipment, and is safer. Even though quantitative evaluation of vessel flow is not possible with ICG angiography, this shortcoming can be overcome with the combined use of intraoperative Doppler sonography with ICG angiography. Doppler sonography not only enables quantitative analysis of VA blood flow; this tool can also be used to identify the VA even inside the screw trajectory. Thus, combined ICG angiography and Doppler sonography may be a valuable intraoperative monitoring method with which the patency and characteristics of the VA can be assessed, especially in high-risk patients and by inexperienced surgeons, to avoid IVAI during any CVJ surgery.

\section{References}

1. Yi HJ, Hong JT, Lee JB, et al. Analysis of risk factors for posterior $\mathrm{C} 1$ screw-related complication: a retrospective study of 358 posterior C1 screws. Oper Neurosurg (Hagerstown). 2019;17(5):509-517.

2. Hong JT, Kim IS, Kim JY, et al. Risk factor analysis and decision-making of surgical strategy for V3 segment anomaly: significance of preoperative CT angiography for posterior $\mathrm{Cl}$ instrumentation. Spine J. 2016;16(9):1055-1061.

3. Takigawa T, Simon P, Espinoza Orías AA, et al. Biomechanical comparison of occiput-C1-C2 fixation techniques: $\mathrm{C} 0-\mathrm{C} 1$ transarticular screw and direct occiput condyle screw. Spine (Phila Pa 1976). 2012;37(12):E696-E701.

4. Hong JT, Takigawa T, Udayakunmar R, et al. Biomechanical effect of the C2 laminar decortication on the stability of $\mathrm{C} 2$ intralaminar screw construct and biomechanical comparison of C2 intralaminar screw and C2 pars screw. Neurosurgery. 2011;69(1 Suppl Operative):ons1-ons7.

5. Hong JT, Takigawa T, Sugisaki K, et al. Biomechanical and morphometric evaluation of occipital condyle for occipitocervical segmental fixation. Neurol Med Chir (Tokyo). 2011; 51(10):701-706.

6. Hong JT, Kim TH, Kim IS, et al. The effect of patient age on the internal carotid artery location around the atlas. J Neurosurg Spine. 2010;12(6):613-618.

7. Lee JJ, Hong JT, Kim IS, et al. Significance of multimodal intraoperative monitoring during surgery in patients with cra- niovertebral junction pathology. World Neurosurg. 2018;118: e887-e894.

8. Lee HJ, Kim JH, Kim IS, Hong JT. Anatomical evaluation of the vertebral artery (V2) and its influence in cervical spine surgery. Clin Neurol Neurosurg. 2018;174:80-85.

9. Hong JT, Lee SW, Son BC, et al. Analysis of anatomical variations of bone and vascular structures around the posterior atlantal arch using three-dimensional computed tomography angiography. J Neurosurg Spine. 2008;8(3):230-236.

10. Hong JT, Park DK, Lee MJ, et al. Anatomical variations of the vertebral artery segment in the lower cervical spine: analysis by three-dimensional computed tomography angiography. Spine (Phila Pa 1976). 2008;33(22):2422-2426.

11. Hong JT, Sung JH, Son BC, et al. Significance of laminar screw fixation in the subaxial cervical spine. Spine (Phila Pa 1976). 2008;33(16):1739-1743.

12. Hong JT, Jang WY, Kim IS, et al. Posterior C1 stabilization using superior lateral mass as an entry point in a case with vertebral artery anomaly: technical case report. Neurosurgery. 2011;68(1 Suppl Operative):246-249.

13. Kim IS, Hong JT, Jang WY, et al. Surgical treatment of os odontoideum. J Clin Neurosci. 2011;18(4):481-484.

14. Kim JT, Lee HJ, Kim JH, Hong JT. Quantitative analysis of unusual entrance of the vertebral artery into the cervical foramen (V2 segment) and its clinical implications. Eur Spine J. 2016;25(12):4188-4194.

15. Kim MS, Kim JY, Kim IS, et al. The effect of C1 bursting fracture on comparative anatomical relationship between the internal carotid artery and the atlas. Eur Spine J. 2016;25(1): 103-109.

16. Song MS, Lee HJ, Kim JT, et al. Ponticulus posticus: morphometric analysis and its anatomical implications for occipito-cervical fusion. Clin Neurol Neurosurg. 2017;157:76-81.

17. Hongo K, Kobayashi S, Okudera H, et al. Noninvasive cerebral optical spectroscopy: depth-resolved measurements of cerebral haemodynamics using indocyanine green. Neurol Res. 1995;17(2):89-93.

18. Raabe A, Beck J, Gerlach R, et al. Near-infrared indocyanine green video angiography: a new method for intraoperative assessment of vascular flow. Neurosurgery. 2003;52(1):132-139.

19. Kotil K, Kilincer C. Sizes of the transverse foramina correlate with blood flow and dominance of vertebral arteries. Spine J. 2014;14(6):933-937.

20. Bulut MD, Alpayci M, Şenköy E, et al. Decreased vertebral artery hemodynamics in patients with loss of cervical lordosis. Med Sci Monit. 2016;22:495-500.

21. Joaquim AF, Mudo ML, Tan LA, Riew KD. Posterior subaxial cervical spine screw fixation: a review of techniques. Global Spine J. 2018;8(7):751-760.

22. Park JH, Hong JT, Lee JB, Kim IS. Clinical analysis of radiologic measurements in patients with basilar invagination. World Neurosurg. 2019;131:e108-e115.

23. Gok M, Aydin E, Guneyli S, et al. Iatrogenic vascular injuries due to spinal surgeries: endovascular perspective. Turk Neurosurg. 2018;28(3):469-473.

24. Guan Q, Chen L, Long Y, Xiang Z. Iatrogenic vertebral artery injury during anterior cervical spine surgery: a systematic review. World Neurosurg. 2017;106:715-722.

25. Schroeder GD, Hsu WK. Vertebral artery injuries in cervical spine surgery. Surg Neurol Int. 2013;4(suppl 5):S362-S367.

26. Kim CH, Hong JT, Chung CK, et al. Intraoperative electrophysiological monitoring during posterior craniocervical distraction and realignment for congenital craniocervical anomaly. Eur Spine J. 2015;24(4):671-678.

27. Lee HJ, Kim IS, Sung JH, et al. Significance of multimodal intraoperative monitoring for the posterior cervical spine surgery. Clin Neurol Neurosurg. 2016;143:9-14.

28. Kim IS, Hong JT, Lee JJ, et al. A novel technique for cervical laminoplasty fusion: simultaneously enhancing stabiliza- 
tion and decompression in various cervical myelopathies: a technical note and outcomes. World Neurosurg. 2018;111: 361-366.

29. Raabe A, Beck J, Seifert V. Technique and image quality of intraoperative indocyanine green angiography during aneurysm surgery using surgical microscope integrated nearinfrared video technology. Zentralbl Neurochir. 2005;66(1): $1-8$.

30. Raabe A, Nakaji P, Beck J, et al. Prospective evaluation of surgical microscope-integrated intraoperative near-infrared indocyanine green videoangiography during aneurysm surgery. J Neurosurg. 2005;103(6):982-989.

31. Colby GP, Coon AL, Sciubba DM, et al. Intraoperative indocyanine green angiography for obliteration of a spinal dural arteriovenous fistula. J Neurosurg Spine. 2009;11(6):705-709.

32. Della Puppa A, Rustemi O, Gioffrè G, et al. Transdural indocyanine green video-angiography of vascular malformations. Acta Neurochir (Wien). 2014;156(9):1761-1767.

33. Endo T, Aizawa-Kohama M, Nagamatsu K, et al. Use of microscope-integrated near-infrared indocyanine green videoangiography in the surgical treatment of intramedullary cavernous malformations: report of 8 cases. J Neurosurg Spine. 2013;18(5):443-449.

34. Schubert GA, Schmieder K, Seiz-Rosenhagen M, Thomé C. ICG videography facilitates interpretation of vascular supply and anatomical landmarks in intramedullary spinal lesions: two case reports. Spine (Phila Pa 1976). 2011;36(12):E811E813.

35. Khurana VG, Seow K, Duke D. Intuitiveness, quality and utility of intraoperative fluorescence videoangiography: Australian neurosurgical experience. Br J Neurosurg. 2010;24(2): $163-172$.

36. Hardesty DA, Thind H, Zabramski JM, et al. Safety, efficacy, and cost of intraoperative indocyanine green angiography compared to intraoperative catheter angiography in cerebral aneurysm surgery. J Clin Neurosci. 2014;21(8):1377-1382.

37. Heo Y, Lee SB, Lee BJ, et al. The learning curve of subaxial cervical pedicle screw placement: how can we avoid neurovascular complications in the initial period? Oper Neurosurg (Hagerstown). 2019;17(6):603-607.

38. Merrill S, Clifton W, Valero-Moreno F, et al. Vertebral artery injury with coinciding unstable cervical spine trauma: mechanisms, evidence-based management, and treatment options. Cureus. 2020;12(3):e7225.
39. AlBayar A, Sullivan PZ, Blue R, et al. Risk of vertebral artery injury and stroke following blunt and penetrating cervical spine trauma: a retrospective review of 729 patients. World Neurosurg. 2019;130:e672-e679.

40. Wei F, Liu Z, Liu X, et al. An approach to primary tumors of the upper cervical spine with spondylectomy using a combined approach: our experience with 19 cases. Spine (Phila Pa 1976). 2018;43(2):81-88.

41. Lee HJ, Hong JT, Kim IS, et al. Analysis of measurement accuracy for craniovertebral junction pathology: most reliable method for cephalometric analysis. J Korean Neurosurg Soc. 2013;54(4):275-279.

42. Lofrese G, Cultrera F, Visani J, et al. Intraoperative Doppler ultrasound as a means of preventing vertebral artery injury during Goel and Harms C1-C2 posterior arthrodesis: technical note. J Neurosurg Spine. 2019;31(6):824-830.

\section{Disclosures}

The authors report no conflict of interest concerning the materials or methods used in this study or the findings specified in this paper.

\section{Author Contributions}

Conception and design: Hong, DH Lee. Acquisition of data: DH Lee, Park, JJ Lee, JB Lee, HJ Lee, Hur. Analysis and interpretation of data: Hong, DH Lee, JB Lee, HJ Lee, Kim, Hur. Drafting the article: DH Lee. Critically revising the article: Hong. Reviewed submitted version of manuscript: Hong, Kim. Approved the final version of the manuscript on behalf of all authors: Hong. Statistical analysis: DH Lee. Administrative/technical/material support: Hong. Study supervision: Hong.

\section{Correspondence}

Jae Taek Hong: Eunpyeong St. Mary's Hospital, The Catholic University of Korea, Seoul, South Korea.jatagi15@gmail.com. 